\title{
CURRENT RESEARCH USING THE ANL HIGH VOLTAGE ELECTRON MICROSCOPE- TANDEM ACCELERATOR FACILITY *
}

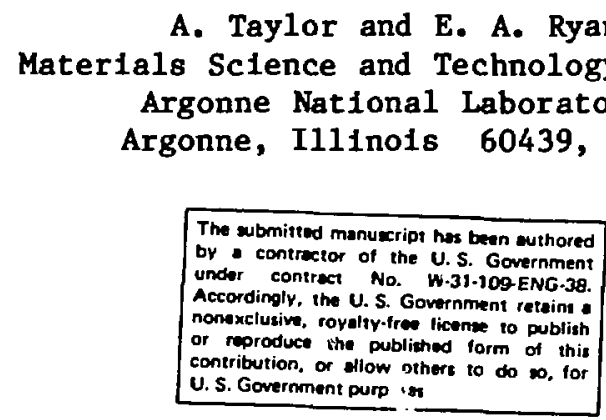

CONF-841117--46

by abmirted manuzcript has been authored

uncer contractor of the U.S. Government

Accordingly, the U.S. W.31.109-ENG-38.

nonsxclusive, royalty-fres license to publish

the publithed form of this

U. S. Government purp is

NOVEMBER 1984

DE85 006911

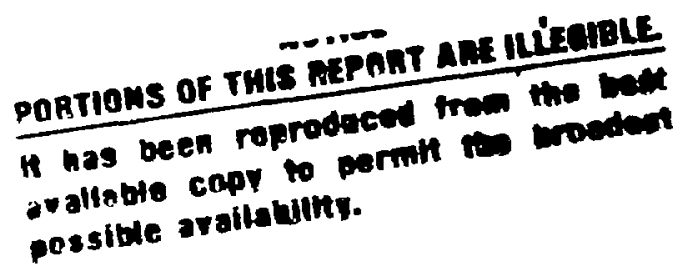

\section{DISCLAIMER}

This report was prepared as an account of work sponsored by an agency of the United States Government. Neither the United States Government nor any agency therec.; nor any of their employees, makes any warranty, express or implied, or assumes any legal liability or responsibility for the accuracy, completeness, or usefulness of any information, apparatus, product, or process disclosed, or represents that its use would not infringe privately owned rights. Reference herein to any specific commercial product, process, or service by trade name, trademark, manufacturer, or otherwise does not necessarily constitute or imply its endorsement, recommendation, or favoring by the United States Government or any agency thereof. The views and opinions of authors expressed herein do not necessarily state or reflect those of the United States Government or any agency thereof.

*This work was supported by the U.S. Department of Energy.

To be presented at the Conference on the Applications of Accelerators in Research and Industry, November 12-14, 1984, Denton, Texas. 
CURRENT RESEARCH USING THE ANL HIGH VOLTAGE ELECTRON MICROSCOPETANDEM ACCELERATOR FACILITY*

\author{
A. Taylor and E. A. Ryan \\ Materials Science and Technology Divison \\ Argonne Nationai Laboratory \\ Argonne, Illinois 60439, USA
}

\title{
SUIMARY
}

Recent work at the Argonne National Laboratory, (ANL), HVEM - Tandem Accelerator user facility is summarized: Direct observation of cluster defects formed by in-situ ion irradiation at low temperature using the ionbeam interface has led to important fundamental results on defect production processes. Results on solute segregation at elevated temperatures induced by electron and ion 1rradiation are reported. Other published work is briefly summarized and/or referenced.

\section{IHTRODOCTION}

A descripcion of the ANL HVEM-Tandem Accelerator Facilsty together with system performance was presented at the Denton Conference in 1982 [1]. Operational experience with the system has shown that Ion beam current densities of $10 \mathrm{microamp} / \mathrm{cm}^{2}$ can be delivered to sample $1 \mathrm{n}$ the HVEM. This represents an order of magnitude increase over design alm. This improvement permits complete ion implantations at medium dose levels to be observed in-situ. The skim cup used to monitor the ion beam inside the HVEM that was described earlier has been upgraded, the new configuration is shown in Fig. 1. This is a combined skim cup and movable Faraday cup. The device permits continuous monitoring of the ion beam and thereby improves the

\footnotetext{
*Th1s werk is supported by the U.S. Department of Energy.
} 
accuracy of measurements of fluences delivered to the specimen. A double tilt He cooled specimen rod for the HVEM will be tested shortly. This will permit wider selection of lmaging conditions than is presently available with the single tilt stage [2].

A sumnary of recent radiation damage related work is given in Table I. This work includes measurements of the energy to form single Frenkel defects at low temperature, cluster damage production by heavy Ion Irradiation, and defect-solute interaction at elevated temperature. The work which has resulted in Important new findings has direct relevance to the understanding of radiation damage in reactors, ion implantation processes, and sputtering behavior. Table 2 contains a list of work mostly in progress and is included to illustrate the wide variety of studies being carried out at this unique Department of Energy, national user facility.

\section{RADIATION DAMAGE STUDIES AT LON TEMPBRATURES}

The work of $\mathrm{KIng}$ et al. [2] on damage production by electrons in fcc metals has led to a reevaluation of the Frenkel pair threshold energy damage surface in copper crystals and to the determination of more realistic damage functions for copper and nickel polycrystals [3] in the low energy knock-on regime. The new damage functions correct the commonly employed "Modified Kinchin and Pease" formula $[4,5]$ which considerably overestimates the number of defects formed in the low energy regine.

Several groups of workers, see Table I, are now exploiting the capability to carry out In-8itu Ion Irradiations at low temperatures where vacancles are immoblle in order to measure the structure and formation efficlencies of heavy Ion Induced cascades and to determine under what clrcu-stances their vacancy rich cores collapse Into dislacation loops. A brief review of this 
work was recently presented at the $S M^{2}$ IB Conference at Heidelberg, September 1984 and w11 be published soon [6]. In the case of pure metals, the dislocation loops at the collapsed cascade sites are visible and the defect formation efficiency must be obtained from measurements of the ion fluence Incident upon the specimen folls. However, in the case of single crystal folls formed from ordered $\mathrm{Cu}_{3} \mathrm{Au}$ alloy [7] extenaive study of contrast and imaging conditions has shown that it is possible to choose imaging conditions that render visible the disordered zones formed at all cascade sites and to distinguish those sites that have collapsed into dislocation loops. The method is therefore absolute and can also be used to calibrate the dosimetry system. An example of a complementary pair of 1mages is shown in Fig. 2. The photomicrograph (a) is a dark field image using the superlattice reflection $g=\{110\}$, and shows the displacement cascade through structure factor contrast, while micrograph (b) is a bright field kinetic image using $g=\{220\}$ showing the dislocation loop through strain contrast. Both images were taken at low temperatures following $100 \mathrm{keV} \mathrm{Ar}^{+}$irradiation at $10 \mathrm{~K}$ and in this micrograph all disordered zones have collapsed. The number density, size distribution, and structure of the cluster defects have been examined as a function of particle mass, fluence, and energy, and important new findings have emerged. In general, it is found that in $\mathrm{fcc} \mathrm{Cu}, \mathrm{Ag}, \mathrm{Au},[8]$ and $\mathrm{Cu}_{3} \mathrm{Au}$, the defect formation efficiences are high at low temperature where vacancy motion is frozen-in, are linear with ion dose, and independent of energy above $50 \mathrm{keV}$. Thermal annealing to room temperature does not increase the number of loopa following low temperature irradiation, but in the case of $\mathrm{Cu}_{3} \mathrm{Au}$ there is a systemmatic $\approx 20 \%$ increase in defect efficiency when the irradiation temperature 18 raised to $300 \mathrm{~K}$. The results show that the vacancy rich cores of the cascades collapse "athermally" during the thermal spike phase of cascade 
formation 1.e., during the initial $10^{-10}-10^{-12}$ seconds. A detailed Interpretation of the $\mathrm{Cu}_{3} \mathrm{Au}$ data based on the thesis work of Black will be published soon.

In contrast with the above fcc metals, the cascade collapse behavior of Iron [9] when irradiated at $40 \mathrm{~K}$ with self Ions exhibits a dose dependence exponent of $3 / 2$, and a threshold dose of $8 \times 10^{12}$ particles $/ \mathrm{cm}^{2}$. Threshold doses of simflar magnitudes are also observed in nickel [10]. The results Indicate among other things that cascade overlap is necessary to cause cascades to collapse into dislocation loops, confirming a postulate made by Dunlop et al.[11] to explain their resistivity data for neutron irradiated Iron.

\section{RADIATION DAKAGE STUDIES AT RIBVATED TBMPBRATURBS}

In-situ electron 1rradiations of reactor materials in the HVEM is an important tool in the study of radiation damage in the vold swelling regime of technological 1mportant $\mathrm{Fe}-\mathrm{N} 1-\mathrm{Cr}$ based alloys. However, because of differences between the displacement damage production in bulk samples irradiated in the reactors, and thin folls irradiated with focused electron beams in the HVEM, the correlation between data has proved difficult. Because of the need tn understand the damage mechanisms in both nuclear and fusion reactors, Further work is necessary. Groups working at the ANL facility using model alloys have recently demonstrated two important results impacting on such work. In the f1rst study Régnier and co-workers $[11,12]$ have shown that in alloys composed of elements with widely differing $Z^{\prime} s$, radiation damage can occur below the defect tormation thresholds for the solvent elements. In the second study, Okamoto et al. $[13,14]$ have quantified the redistribution of solute elements in electron and proton Irradiations where there are steep gradients in the defect production profiles. 
In the work of Regnier and co-workers, it is shown that atomic displacement of the heavier solvent element can occur through energy transferring collisions from the lighter solvent. In the case of electron 1rradiations made in-situ in the HVEM on Pt-C [11] and N1-Be alloys [12], electron energles well below the energy to form Frenkel pairs in the Pt or $\mathrm{Ni}$, result in visible effects. In $\mathrm{Fig} .3$, 1t is shown that an electron dose of $7.1 \times 10^{22} / \mathrm{cm}^{2}$ at $350 \mathrm{kV}$ delivered to a sample at $450 \mathrm{C}$ results in both dislocation climb and segregation $\rightarrow f$ Be to the internal sinks.

In alloys, irradiation can result in significant mass transport of solute elements through what is termed "radiation induced segregation". Solutes with significantly differing atom size to the solvent may be transported through coupling to the internal fluxes of point defects characteristic of the Irradiation fleld. The flux of oversize solutes, Js, moves in the opposite direction to the defect flux, - Jd, whereas undersize solutes may move in the same direction, 1.e., +Jd. From Fick's law, it can be seen that the local enrichment or depletion of solute $C_{S}$ is determined by the sense and magnitude In the curvature of the defect concentration profile, Cd viz

$$
\frac{\partial C_{s}}{\partial t}=\quad \mp \nabla J_{s} \quad \propto \quad \pm \nabla^{2} C d
$$

Some examples where the distribution of solutes after irradiation have been successfully compared with computer calculations are given in Figs. 4, 5, and 6. The microstructure of a $\mathrm{N1}-12.7 \mathrm{a} / \mathrm{O} \mathrm{Si}$ alloy irradiated at $500 \mathrm{C}$ with $250 \mathrm{keV}$ protons and sectioned perpendicular to the beam direction 18 shown in F1g. 4 together with the calculated damage rate, defect concentration, and accumulation $\nabla^{2}$ Cd versus depth. The undersized solute, Si flows out of the peak damage zone glving rise to a depletion of $\mathrm{Ni}_{3} \mathrm{Si}$ precipitates in the 
region of intense damage. Defects escaping to the free surface transport solute and cause the formation of a surface film. By contrast, in the cases of electron irradiations of foils in the HVEM, the axial dose rate is uniform whereas strong gradients exist in the radial or lateral directions, Fig. 5 lower left. The structures developed in a solid solution $\mathrm{Ni}-10 \mathrm{a} / \mathrm{O} \mathrm{Al}$ alloy irradiate to $700 \mathrm{C}$ with $1 \mathrm{MeV}$ electrons at a dose rate of $10^{-3} \mathrm{dpa} / \mathrm{sec}$ is shown in the upper four micrographs. Coherent precipitates, visible because of strain contrast are seen initlally, while incoherent $\mathrm{Ni}_{3} \mathrm{Al}$ are formed later as in the micrograph for 48 mintues irradiation. The aluminum, an oversize solute, segregates both axially and radially, with the axial segregation dominating at short times. The calculated concentration at the center, shows that the Al concentration exceeds the solubility limit only when the slower radial diffusion processes begin to dominate. Blocky $\mathrm{Ni}_{3} \mathrm{Al}$ precipitates can then be seen in the dark field image (lower right). Figure 6 is a comparison of the development of the microstructure as a function of dose for a $12.7 \mathrm{a} / 0$ Al alloy and a 10 a/o Ge alloy (an undersize solute). In the $\mathrm{Ni}-\mathrm{Al}$ case solute flows from an annular region set by the inflection points of the damage rate profile of the electron beam, shown Figure 5 lower left. A dense precipitate core is formed at the center of the beam profile. Figure 6 right shows that for the undersized Ge, axial gradients produced by the flow of defects to the foll surfaces initially cause precipitation to occur at the upper and lower surfaces, but as the solute is gradually drained into the foll by radial diffusion these precipitates redissolve finally depleting the central region of the radiation damage zone of Ge solute. 


\section{OTHER RESEARCH}

In Table II work on Ion implantation, amorphization and radiation effects In oxides are tabulated. Okamoto, Averback, and Stritzker [15] have demonstrated that when the thin bilayer films of $\mathrm{Cu}$ and $\mathrm{BI}$ are mixed by fon bombardment at liquid He temperatures, a metastable amorphous film is formed with a super conducting transition temperature of $5^{\circ} \mathrm{K}$. Donlon, McCune, and Mitche11 [16] have found that in high dose nitrogen implants of aluminum, nitrogen bubbles but noc nitrides are formed. 


\section{REFERENCES}

1. A. Taylor and E. A. Ryan, IEEE Transactions on Nuclear Science, NS-30, No. 2 (1983) 1263.

2. W. E. King, K. L. Merkle, and M. Meshii, J. Nuclear Materials, 117 (1983) 12.

3. W. E. King, K. L. Merkle, A. C. Baily, K. Haga, and M. Meshii, Proceedings of the Seventh International Conference on High Voltage Electron Microscopy, Berkeley, California, August 16-19, 1983, ed. R. M. Fisher et al., LBL-16031, CONF-830819, pp. 133-138.

4. M. J. Norgett, M. T. Robinson, and I. M. Torrens, Nuc1. Eng. Des. 33, 50.

5. M. T. Robinson and O. S. Oen, J. Nuclear Materials 110 (1982) 147.

6. A. Taylor, A. E. Ryan, A. Philippides, J. Wallace, Proceedings of Conference on Surface Modification of Materials by Ion Beams Heidelberg Sept. 1984 to be published in Material Sciences and Engineering.

7. J. Black, M. L. Jenkins, and M. A. Kirk, to be published, Proc. EMAG 83 Guilford, U.K. Aug. 1983.

8. K. Haga, A. C. Baily, W. E. King, K. L. Merkle and M. Meshii, Proceedings of the Seventh International Conference on High Voltage Electron Microscopy, Berkeley, California, August 16-19, 1983, ed. R. M. Fisher et al., LBL-16031, CONF-830819, 139.

9. I. M. Robertson, M. A. Kirk, and W. E. King, Scripta Metallurgica 18 (1984) 317.

10. M. A. Kirk and M. L. Jenkins, private communication.

11. P. G. Régnier, N. Q. Lam, and K. H. Westmacott, J. Nuclear Materials 115 (1983) 286.

12. P. G. Régnier, to be published J. Nuclear Materials, Proceedings of the lst International Conference on Fusion Reactor Materials, Dec. 3-6, 1984, Tokyo, Japan . 
$-9-$

13. T. Muroga, P. R. Okamoto, and H. Whedersich, Radiation Effects Letters, 68 (1983) 163.

14. P. R. Okamoto and C. Allen, private communication.

15. R. S. Averbach, P. R. Okamoto, A. C. Bafly, and B. Stritzker, IBMM 84 , Cornell Unfversity, Ithaca, N.Y. 1984.

16. W. T. Donlon, R. C. McCune, and T. E. Mitche11, Proc. of the 7th International Conference on High Voltage Microscopy, Berkeley, California, Aug. (1983), p. 255. 


\section{FIGURES}

F1g. 1. Column of HVEM showing details of the internal skim cup and movable Faraday cup.

Fig. 2. Electron micrographed $\mathrm{Cu}_{3} \mathrm{Au}$ foil irradiated with $100 \mathrm{keV} \mathrm{Ar}^{+}$tons $\leqslant 40 \mathrm{~K}$. (a) Dark field 1mage showing disordered zones at sites of all ion impacts.

(b) Corresponding bright field image showing dislocation loops formed by collapse of vacancy rich cores at the cascade sites.

Fig. 3. Beryllium segregation to dislocations at electron energy below displacement threshold of Ni. (a) Before irradiation, (b) $1.24 \times 10^{22} \mathrm{e} / \mathrm{cm}^{2}$, (c) $7.1 \times 10^{22} \mathrm{e} / \mathrm{cm}^{2}, \overrightarrow{\mathrm{h}} \sim[011], \overrightarrow{\mathrm{g}}=[200]$.

Fig. 4. Showing the correlation between the solute accumulation profile $\nabla^{2}$ Cd which was calculated from the damage rate pruductions curve for $250 \mathrm{keV}$ protons incident on $\mathrm{Ni}-12.7$ ajo $\mathrm{SI}$ (upper) and the distribution of $\mathrm{Ni}_{3} \mathrm{Si}$ precipitates observed following irradiation at temperature $500 \mathrm{C}$ (lower).

Fig. 5. Illustrating the influence of strong defect gradients produced by insitu I MeV $\varepsilon^{-}$irradiations on the axial and lateral flow of solutes in $\mathrm{Ni}-10 \mathrm{a} / \mathrm{O} \mathrm{Al}$ alloys at $700 \mathrm{C}$. 
Fig. 6. Micrographs showing contrasting solute redistribution effects during 1 MeV $\varepsilon^{-}$irradiation at elevated temperatures. Left column, Ni-12.7\% Al alloy in which solid solute and defect flows are opposed and for Ni-10 a/o Ge (right column) where flows are parallel. 
Table 1. Fundamental Studies on Defect Production.

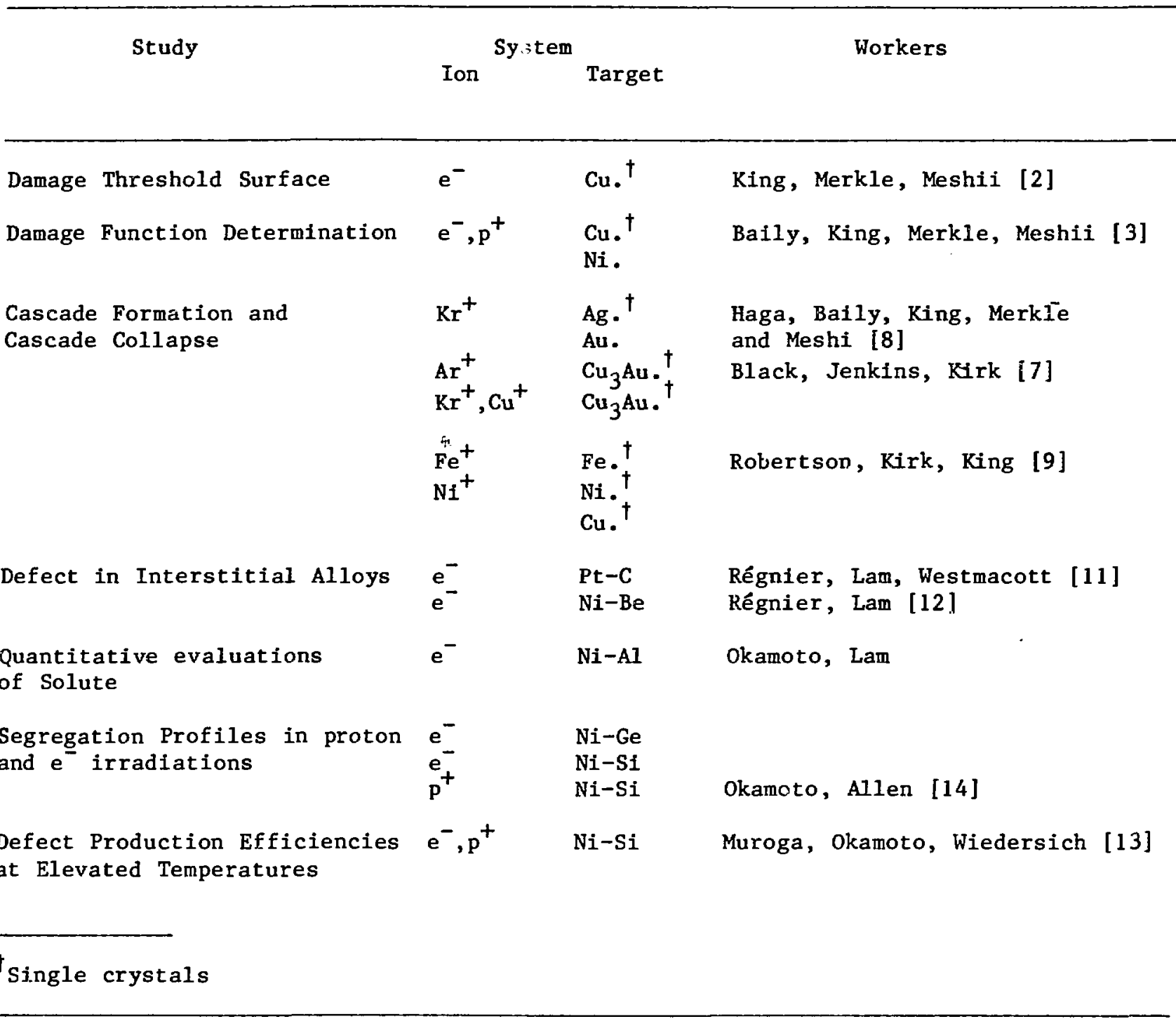


Table 2. Studies of Ion Induced Amorphization, Ion Implantation, and Radiation Damage of Oxides and Glasses.

$$
\text { Study }
$$

$$
\begin{gathered}
\text { Systern } \\
\text { Ion Tazset }
\end{gathered}
$$

Workers

Okamoto, Averback, Stritzker [15] Okamcto, Averback *

Seidman, Okamoto *

Jenkins, Robertson, Kirk *

DeNatale, Howitt *

Mitchell, Lee, Jenkins*

Don?on, McCune, Mitchell [16]

Don? on, McCune, Mitchell [16]

Nitride Formation by Implantation

$$
\mathrm{N}_{2}^{+} \rightarrow \mathrm{Al}
$$




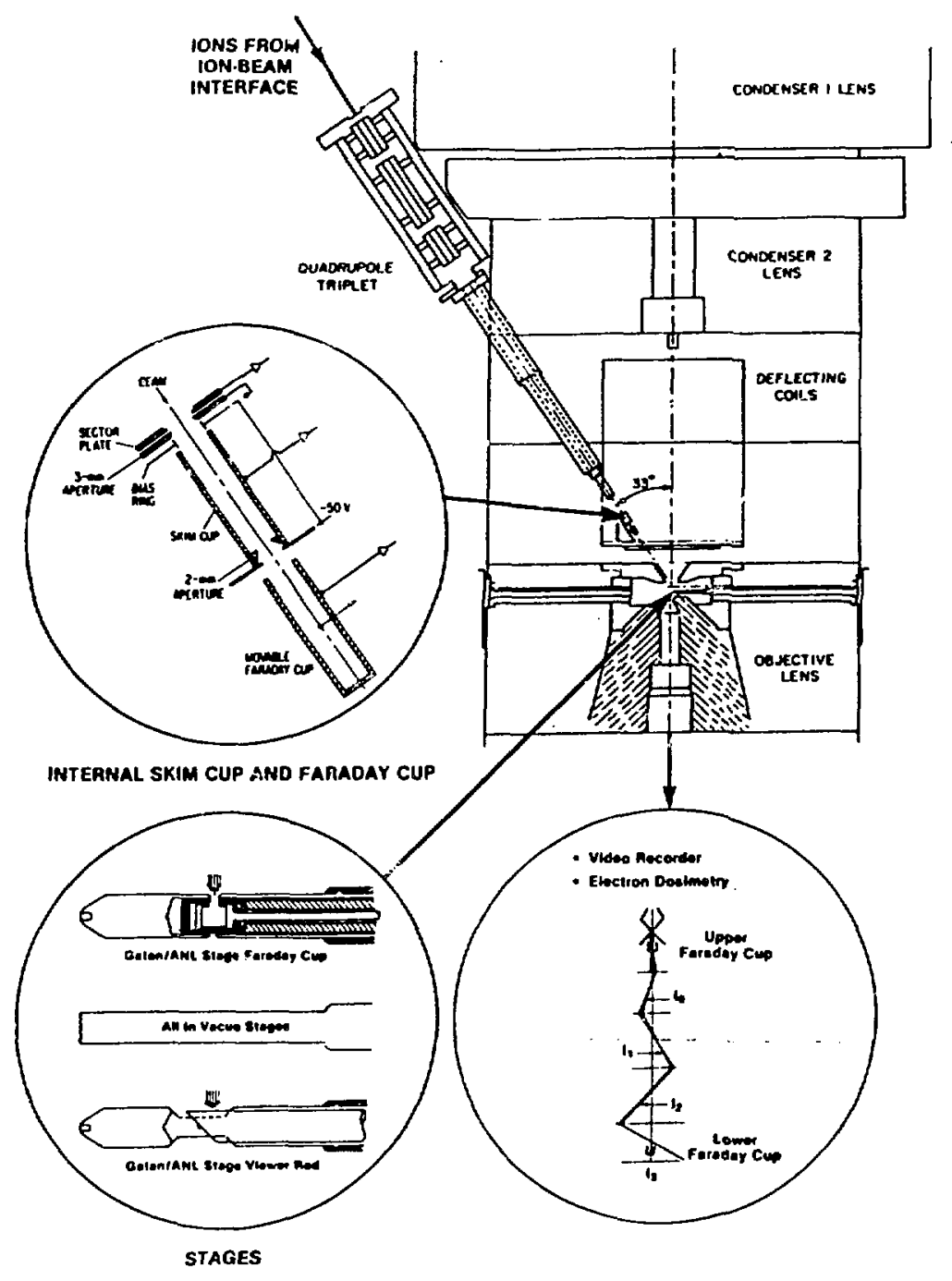

Fig. 1. Colum of HVEM showing details of the internal skim cup and movable Faraday cup. 

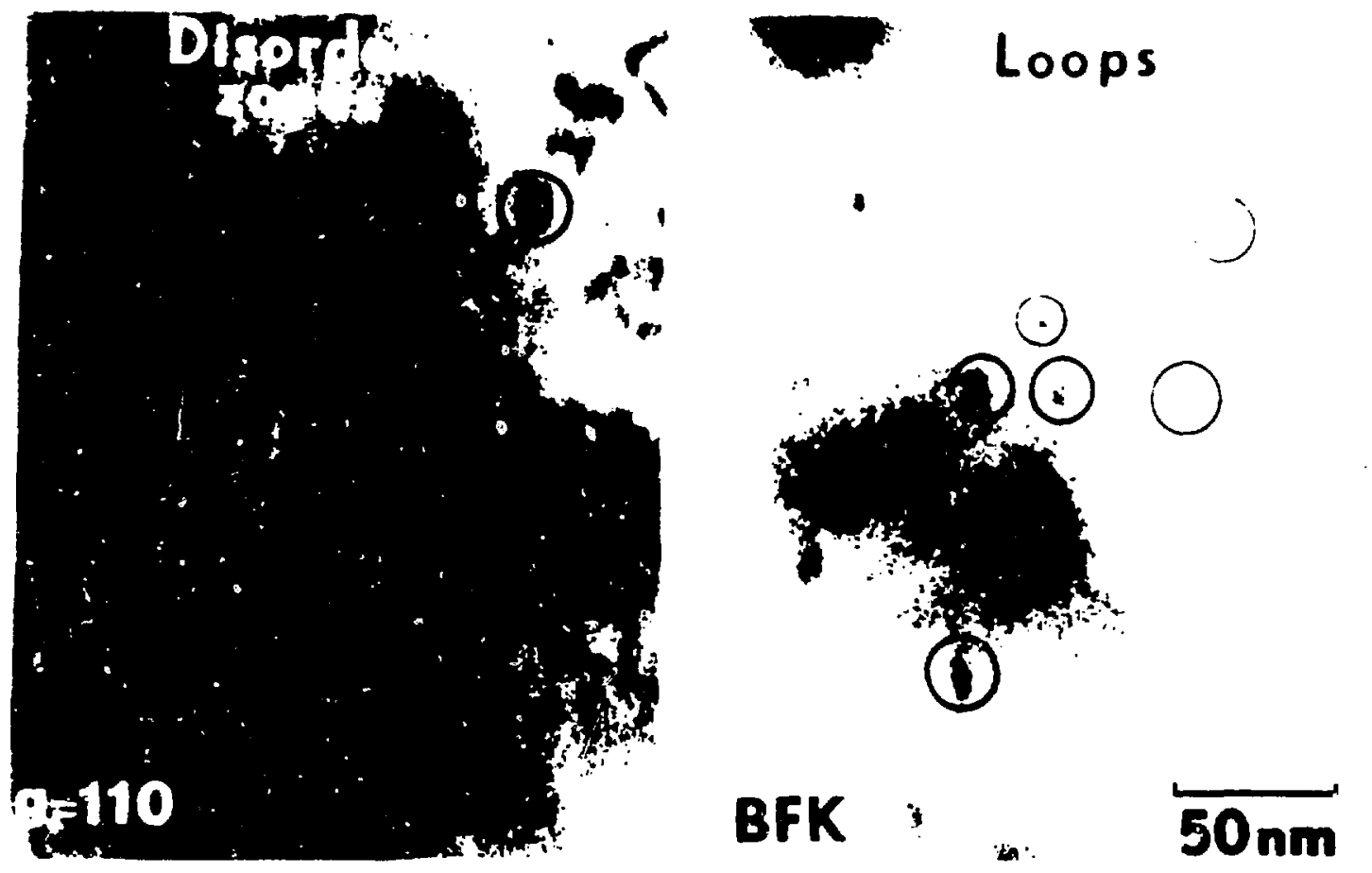

\section{In-sifu irradiation af low temperature $100 \mathrm{keV} \mathrm{Ar}{ }^{+} \rightarrow \mathrm{Cu}_{3} \mathrm{Au}$}

Fig. 2. Electron micrographed $\mathrm{Cu}_{3} \mathrm{Au}$ foll irradiated with $100 \mathrm{keV} \mathrm{Ar}^{+}$Ions $\leq 40 \mathrm{~K}$.

(a) Dark fleld image showing disordered zones at sites of all ion impacts.

(b) Corresponding bright field image showing dislocation loops formed by collapse of vacancy rich cores at the cascade sites. 

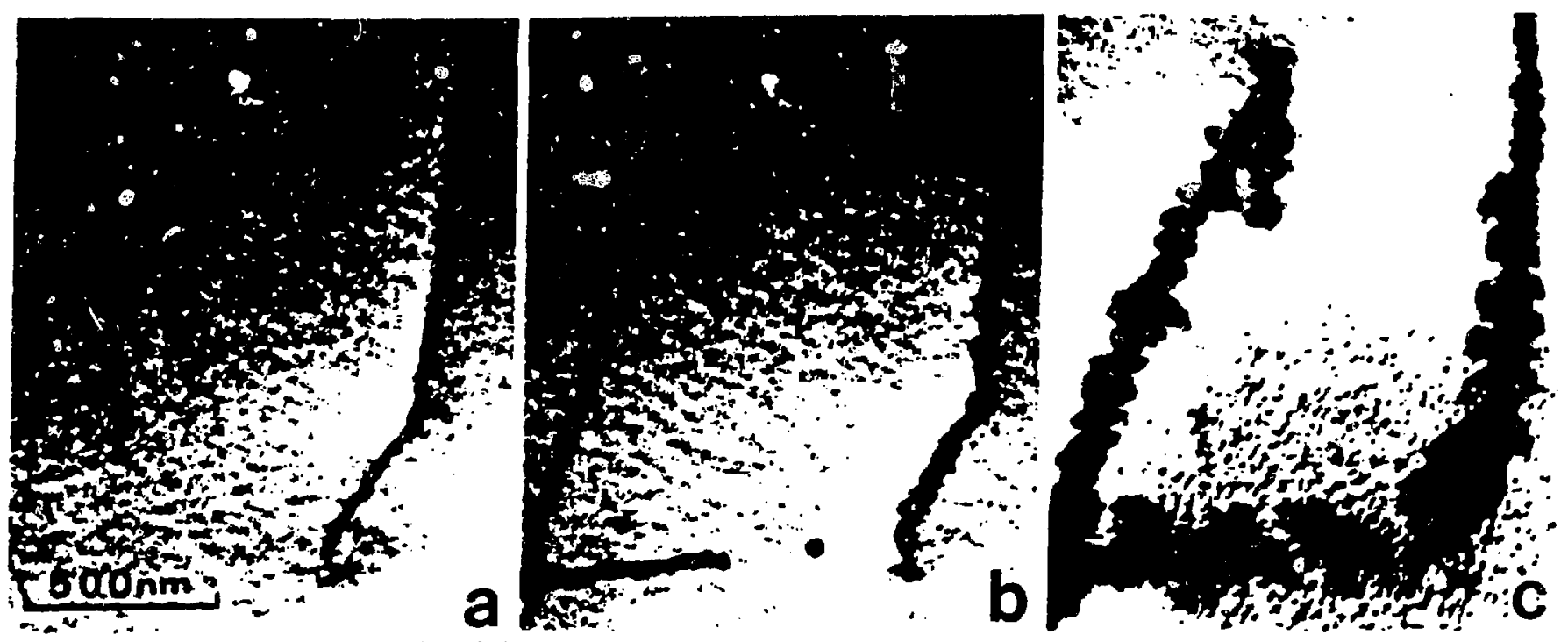

Fig. 3. Beryllium segregation to dislocations at electron energy below displacement threshold of $\mathrm{N1}$. (a) Before Irradiation,
(b) $1.24 \times 10^{22} \mathrm{e} / \mathrm{cm}^{2}$,
(c) $7.1 \times 10^{22} \mathrm{e} / \mathrm{cm}^{2}, \overrightarrow{\mathrm{h}} \sim[011], \stackrel{+}{\mathrm{g}}=[200]$. 

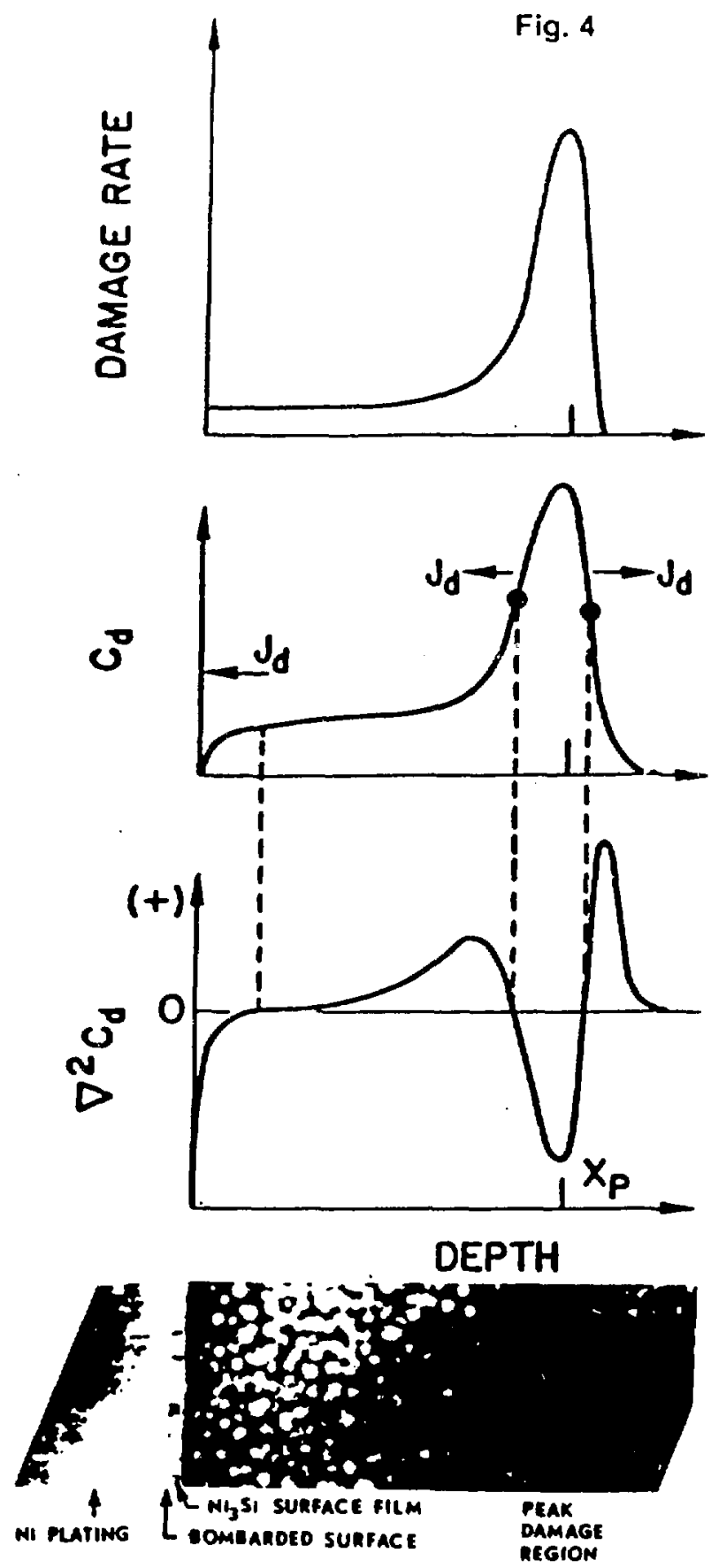

Fig. 4. Showing the correlation between the solute accumulation profile $\nabla^{2}$ Cd which was calculated from the damage rate productions curve for $250 \mathrm{keV}$ protons incident on $\mathrm{NI}-12.7 \mathrm{a} / 0 \mathrm{SI}$ (upper) and the distribution of $\mathrm{Ni}_{3} \mathrm{SI}$ prectpitates observed following irradiation at temperature $500 \mathrm{C}$ (lower). 

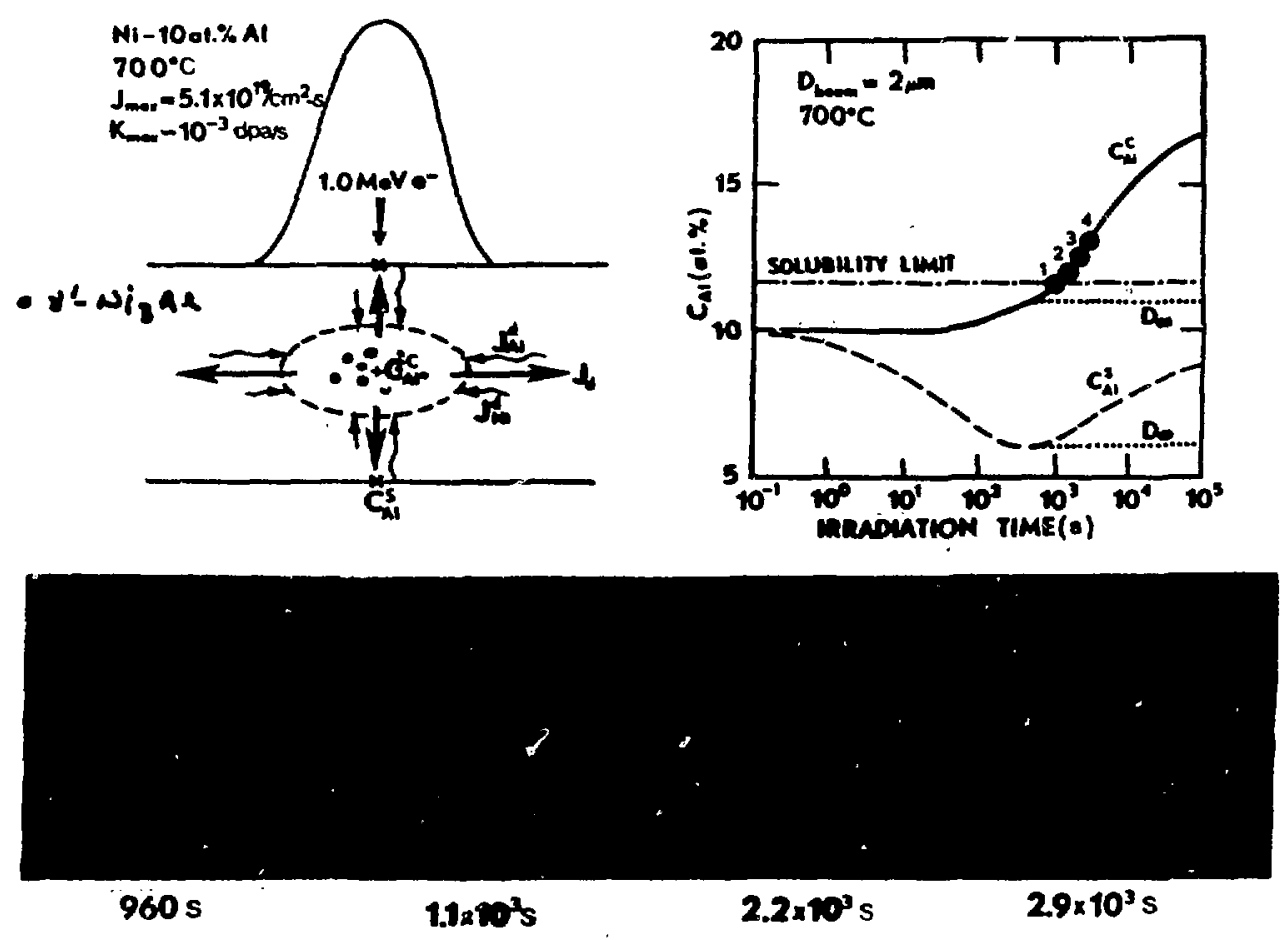

Fig. 5. Illustrating the influence of strong defect gradients produced by insitu $1 \mathrm{MeV} \varepsilon^{-}$irradiations on the axial and lateral flow of solutes in Ni-10 a/o Al alloys at $700 \mathrm{C}$. 


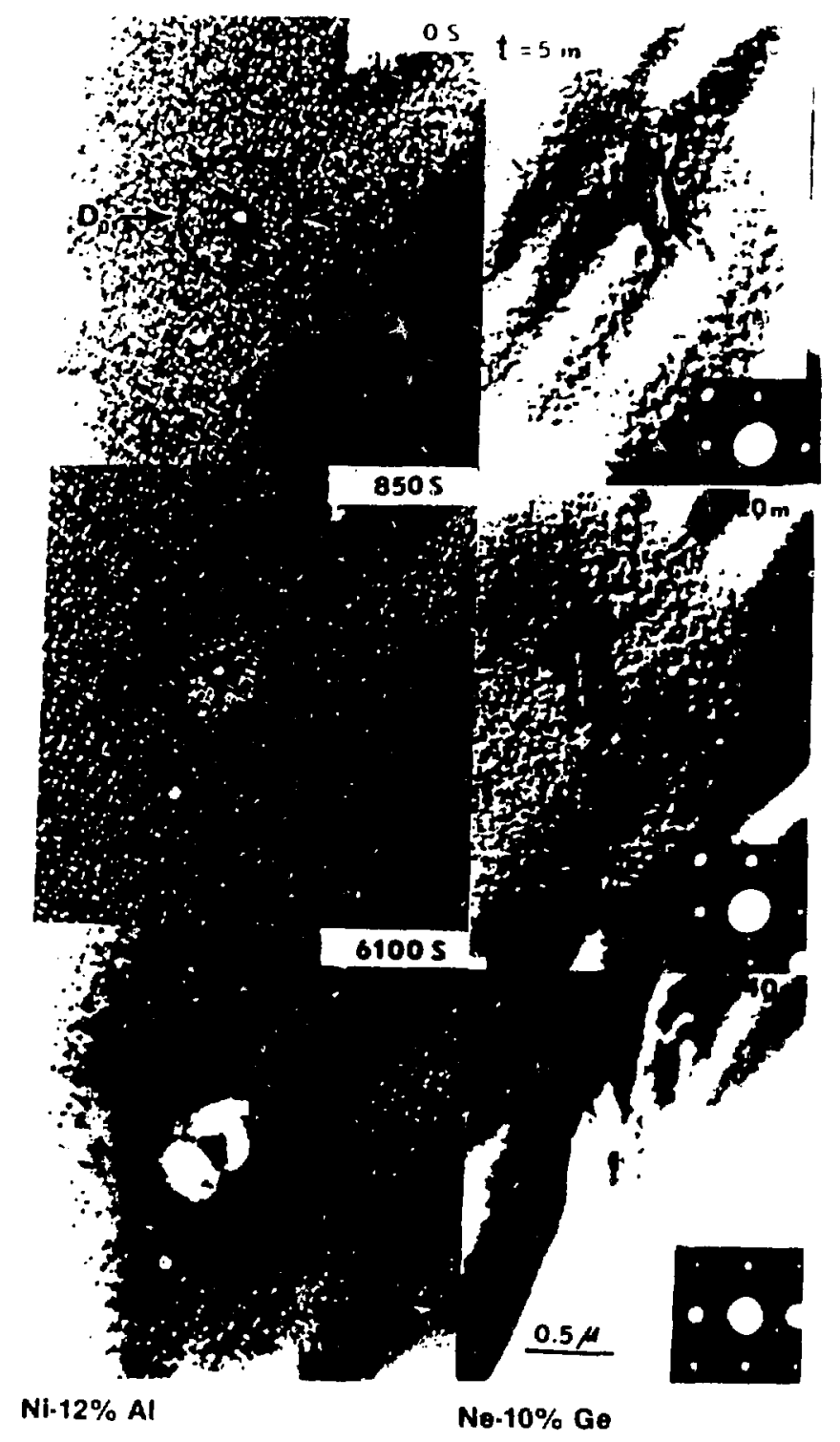

Fig. 6. Micrographs showing contrasting solute redistribution effects during 1 $\mathrm{MeV} \varepsilon^{-}$irradiation at elevated temperatures. Left column, Ni-12.7\% Al alloy In which solid solute and defect flows are opposed and for $\mathrm{N}-10$ a/o Ge (right column) where flows are parallel. 